\title{
Tracking Errors of Exchange Traded Funds in Bursa Malaysia
}

\author{
Alfred Ing-Soon $\mathrm{Ku}$ \\ RHB Investment Bank Berhad \\ 102, Pusat Pedada, Jalan Pedada, 96000 Sibu, Sarawak, Malaysia \\ Tel: 60-84-329214Ｅ-mail: alfredku85@gmail.com \\ Venus Khim-Sen Liew (Corresponding Author) \\ Faculty of Economics and Business, Universiti Malaysia Sarawak \\ Jalan Datuk Mohammad Musa, 94300 Kota Samarahan, Sarawak \\ Tel: 60-82-584291Ｅ-mail: ksliew@unimas.my \\ Chin-Hong Puah \\ Faculty of Economics and Business, Universiti Malaysia Sarawak \\ Jalan Datuk Mohammad Musa, 94300 Kota Samarahan, Sarawak \\ Tel: 60-82-584294Ｅ-mail: chpuah@unimas.my
}

Received: August 7, 2019 Accepted: Nov 7, 2019 Published: December 1, 2019

doi:10.5296/ajfa.v11i2.15235 URL: https://doi.org/10.5296/ajfa.v11i2.15235

\begin{abstract}
This study measures the tracking errors of exchange traded funds (ETFs) listed in Bursa Malaysia. Five measures of tracking errors are estimated in this study for the seven ETFs involved. Overall, the best ETF is METFAPA with the least tracking error. The ranking of the remainder ETFs, in the ascending order of tracking error is MYETFID, METFSID, MYETFDJ, CIMC50, FBMKLCI-EA and CIMBA40 (highest tracking error). The findings in this study is expected to provide clue for passive institutional and retail investors on their selection of ETFs to mimic the portfolio of the desired underlying assets. Moreover, it is anticipated that these findings will motivate the improvement in the tracking ability of the existing ETFs, solicit more follow up studies to encourage the development of new ETFs and increase the participation of investors.
\end{abstract}

Keywords: Exchanged Traded Fund, Bursa Malaysia, Passive Managment, Tracking Error 


\section{Introduction}

Exchange Traded Fund (ETF) is invented to replicate performance of underlying index in the stocks, bonds, commodities or foreign currencies markets. ETFs are pooled-investment funds that allow investors to own the undelying assets. As they are traded directly on stock exchange, their prices fluctuate throughout the trading day due to buying and selling activities like stocks. The world's first ETF, Toronto Index Participation units (TIPs), was listed in Canada in 1990, less than 3 decades ago (Note 1). Despite the relative shorter history of existence compared to their underlying financial assets, ETFs are accepted by worldwide institutional and retail investors, as they provide the cheaptest way to massively diversify their investments. ETFs enjoy strong growth in terms of numbers of ETFs and asset under management (AUM). As of August 2017, ETFs hold approximately US\$4.38 trillion of assets globally (Note 2). According to a survey conducted by Pricewaterhouse Cooper (2015), 75\% of the participants around the globe are confident that ETFs assets will grow to US\$ 5 trillion by 2020.

ETFs performance are substantially less researched compared to investments performance on stocks, bonds and commodities. Elton, Gruber, Comer and Li (2002) were among the first to provide an analysis of the Spider ETF, which tracks the Standard \& Poor's 500 Index. They found that, on average, the Spider traded at a discount of $0.18 \%$ to its NAV and $1.8 \%$ below low cost index fund. This was mainly due to the management fees and holding dividend in the non-interest bearing account (Note 3). In a seperate endavour, Gastineau (2004) investigated the operating efficiency of the funds. Gastineau (2004) claimed that ETFs underperformed relative to their benchmarks and mutual funds, which are actively-managed pooled investment products widely known to investors. He argued that the underperformance is due to the reluctance of ETFs managers to timely adjust the index if underlying benchmark makes any changes.

Since ETFs are invented to track the underlying index, it is logic to evaluate their tracking errors. Tracking error is defined as difference between the return of ETF and its underlying benchmark. Engle and Sarkar (2006) did a comprehensive analysis on tracking error of ETFs listed in the U.S. They included a larger number of both domestic and international ETFs in the US. They found that domestic ETF only showed small deviations that typically last for a few minutes only. Contradictory, international ETF showed persistent higher premium or discount to compared the net asset values of the underlying assets (NAVs). The relatively high tracking errors of international ETFs was also observed by Jares and Javin (2004). Both of them opined that larger tracking errors were attributed to timing mismatch between the pricing of ETFs and NAVs that arose due to time different of trading hours. Milonas and Rompotis (2006) found an average tracking error of $1.02 \%$ among 36 Swiss ETFs. Shin and Soydemir (2010) estimated tracking errors from 26 ETFs covering 20 iShares Morgan Stanley Capital International (MSCI) Country Funds and 6 iShares Broad U.S. Equity Market Funds. They documented persistent tracking errors that range from $0.001 \%$ to $0.014 \%$ on daily basis. They further showed that the tracking errors were due to expenses, dividends and exchange rates. Blitz and Huij (2011) pointed out that global emerging market (GEM) ETF posed larger tracking error due to the larger dispersion of stock return. Bassie (2012) reported that tracking errors of ETFs listed in Europe were relatively small and stable over time. Qiao (2013) reported 
that ETFs in the US provide excess return against underlying benchmark but do not outperform relative mutual funds based on historical data from 2011 until 2013. Heino and Kromlid (2014) showed tracking errors of $0.57 \%$ for U.S. ETFs. Dinglestad (2015) documented that the ETFs listed in London Stock Exchange (LSE) had small tracking errors and they were decreasing over time.

As for Asia Pacific, Gallagher and Segara (2006) reported that ETFs traded on the Australian stock exchange produced the same return as their underlying benchmark before costs. Lin, Chan and Hsu (2005) revealed that among all Taiwan listed ETFs, Taiwan Top 50 Tracker Fund (TTT) which tracks Taiwan 50 Index, was price efficient. It almost produces identical return to Taiwan index. However, Lin and Chou (2006) reported that tracking errors of TTT more often occurred during the companies' dividend payment period. In a seperate endeavor, Chu (2011) documented that tracking errors of Hong Kong ETFs are as high as those in the U.S. and Australia. Prasanna (2012) did a thorough analysis on growth and performance of ETF in India and found that CNX 50 generated excess return of 3\% per annum. Li (2013) analyzed 6 ETFs listed on Hong Kong and China which are all tracking Shanghai Shenzen CSI 300 Index and reported that ETFs in emerging market, especially in China showed underperformance in return as compared to the respective indices. The current study attempts to measure the tracking errors of ETFs traded in Bursa Malaysia.

\section{ETFs in Malaysia}

The first ETF was listed on Bursa Malaysia in 2005. It is the ABF Malaysia Index Fund, which is a bond fund that track Markit iBoxx ABF Malaysia Bond Index. The first equity ETF, which is the FTSE Bursa Malaysia KLCI, came in two years later. As of today, the numbers of ETFs increased to eight after a more than a decade of development. ETFs listed on Bursa Malaysia are summarized in Table 1. Development of ETFs in Malaysia have been sluggish. This could attribute to low product awareness among investors and thin trading volume.

There are three ETFs providers in Malaysia. AmInvestment is the pioneer in Malaysia ETF industry. AmInvestment launched Malaysia first and the only bond fund, ABF Malaysia Bond Index Fund and FTSE Bursa Malaysia KLCI, which tracks against Kuala Lumpur Composite Index. i-VCAP Managment is the most active provider, with four funds launched and total asset under management (AUM) amounting to RM343 million. i-VCAP Management, a wholly subsidiary of Value Cap Sdn Bhd, is Islamic ETF provider of Malaysia. CIMBPrincipal Asset Management launched two regional funds in 2010 worth AUM RM15 million in total.

i-VCAP Management launched Malaysia first Islamic ETF, MYETF Dow Jones Islamic Market Malaysia Titan 25. Islamic ETF is ETF that track benchmark index that comprise of securities which are shariah compliant. i-VCAP Management continue its effort in pioneering in Islamic ETFs with conitnuous launching new funds in recent years. MyETF MSCI Malaysia Islamic Dividend, MyETF MSCI South East Asia Islamic Dividend and MyETF Thomson Reutuers Asia Pacific ex-Japan Islamic Agribusiness are among Islamic ETFs that are listed on Bursa Malaysia. 
Trading volume of Malaysia ETFs on exchange have been thin since inception. However, continuous education effort on ETFs by Bursa Malaysia had resulted in $66 \%$ growth in the trading volume with 28.9 million units being traded in 2015 as compared to 17.4 million in previous year. Thus, investors education is crucial in order to increase their participation.

Table 1. ETFs Listed On Bursa Malaysia

\begin{tabular}{|c|c|c|c|c|c|}
\hline $\begin{array}{l}\text { Listing } \\
\text { Year }\end{array}$ & Fund Provider & ETF & Code & Symbol & $\begin{array}{l}\text { Underlying } \\
\text { Index }\end{array}$ \\
\hline 2005 & AmInvestment & $\begin{array}{l}\text { ABF Malaysia } \\
\text { Bond Index } \\
\text { Fund }\end{array}$ & 0800EA & ABFMY1 & $\begin{array}{l}\text { Markit iBoxx } \\
\text { ABF Malaysia } \\
\text { Bond Index }\end{array}$ \\
\hline 2007 & AmInvestment & $\begin{array}{l}\text { FTSE Bursa } \\
\text { Malaysia KLCI }\end{array}$ & 0820EA & $\begin{array}{l}\text { FBMKLCI- } \\
\text { EA }\end{array}$ & $\begin{array}{l}\text { FTSE Bursa } \\
\text { Malaysia KLCI } \\
\text { Index }\end{array}$ \\
\hline 2008 & $\begin{array}{l}\text { i-VCAP } \\
\text { Management }\end{array}$ & $\begin{array}{l}\text { MyETF Dow } \\
\text { Jones Islamic } \\
\text { Market Titan } 25\end{array}$ & $0821 \mathrm{EA}$ & MYETFDJ & $\begin{array}{l}\text { Dow Jones } \\
\text { Islamic Market } \\
\text { Malaysia Titans } \\
25 \text { Index }\end{array}$ \\
\hline 2010 & $\begin{array}{l}\text { CIMB-Principal } \\
\text { Asset } \\
\text { Management }\end{array}$ & $\begin{array}{l}\text { CIMB FTSE } \\
\text { ASEAN } 40 \\
\text { Malaysia }\end{array}$ & 0822EA & CIMBA40 & $\begin{array}{l}\text { FTSE ASEAN } 40 \\
\text { Index }\end{array}$ \\
\hline 2010 & $\begin{array}{l}\text { CIMB-Principal } \\
\text { Asset } \\
\text { Management }\end{array}$ & $\begin{array}{l}\text { CIMB FTSE } \\
\text { China } 50 \text { Index }\end{array}$ & 0823EA & CIMBC50 & $\begin{array}{l}\text { FTSE China } 50 \\
\text { Index }\end{array}$ \\
\hline 2014 & $\begin{array}{l}\text { i-VCAP } \\
\text { Management }\end{array}$ & $\begin{array}{l}\text { MyETF MSCI } \\
\text { Malayisa Islamic } \\
\text { Dividend }\end{array}$ & 0824EA & MYETFID & $\begin{array}{l}\text { MSCI Malaysia } \\
\text { IMI Islamic High } \\
\text { Dividend Yield } \\
10 / 40\end{array}$ \\
\hline 2015 & $\begin{array}{l}\text { i-VCAP } \\
\text { Management }\end{array}$ & $\begin{array}{l}\text { My ETF MSCI } \\
\text { SEA Islamic } \\
\text { Dividend }\end{array}$ & 0825EA & METFSID & $\begin{array}{l}\text { MSCI SEA IMI } \\
\text { Islamic High } \\
\text { Dividend Yield } \\
10 / 40\end{array}$ \\
\hline 2015 & $\begin{array}{l}\text { i-VCAP } \\
\text { Management }\end{array}$ & $\begin{array}{l}\text { My ETF } \\
\text { Thomson } \\
\text { Reuters Asia } \\
\text { acific ex-Japan } \\
\text { Islamic } \\
\text { Agribusiness }\end{array}$ & 0826EA & METFAPA & $\begin{array}{l}\text { Thomson Reuters } \\
\text { Islamic Asia } \\
\text { Pacific ex-Japan } \\
\text { Agribusiness } \\
\text { Index }\end{array}$ \\
\hline
\end{tabular}

Source: Bursa Malaysia (2017)

\section{Data and Methodology}

Weekly closing prices of ETFs and the underlying indices covering the period from June 2007 to May 2016 were employed in this study. The data set was gathered from NextView and 
Bloomberg Terminal. The ETFs examined are all equity ETFs: METFAPA (0826EA), METFSID (0825EA), MYETFID (0824EA), CIMBC50 (0823EA), CIMBA40 (0822EA), MYETFEDJ (0821EA) AND FMBKLCI-EA (0820EA) (Note 4). The plots of these weekly ETFs price movement together with their underlying indices are given in the Appendix. From the figures, apparently these ETFs traced closely their underlying indices over the sample period.

The weekly return of the ETF is calculated as:

$$
F R_{i, t}=\frac{\text { Price }_{i, \mathrm{t}}-\text { Price }_{\mathrm{i}, \mathrm{t}-1}}{\text { Price }_{i, t-1}} \times 100
$$

where,

$F R_{i, t} \quad=\quad$ Return of the ETF $i$ at time $t$;

Price $_{i, t}=$ Price of ETF $i$ at time $t$; and

Price $_{i, t-1}=$ Price of ETF $i$ at time $t-1$.

Meanwhile, weekly return of the underlying index is obtained using the same principle:

$$
I R_{i, t}=\frac{\operatorname{Index}_{i, t}-\operatorname{In} \quad i, t-1}{\operatorname{Index}} \times 100
$$

where,

$I R_{i, t}=$ Return of the underlying index $i$ at time $t$

Index $_{i, t}=$ Price of the underlying index $i$ at time $t ;$; and

Index $_{i, t-1}=\quad$ Price of the underlying index $i$ at time $t-1$.

Tracking error refers to the difference between the return of ETFs and return of indices. The following widely adopted calculations of tracking errors $\left(T E_{1}, T E_{2}\right.$ and $\left.T E_{3}\right)$ are employed in this study (see Dingelstad, 2015):

$$
\begin{gathered}
T E_{1}=F R_{i, t^{-}} I R_{i, t} ; \\
T E_{2}=\frac{\sum_{t=1}^{n}\left|F R_{i, t^{-}} I R_{i, t}\right|}{n} \quad ; \text { and } \\
T E_{3}=\sqrt{\frac{1}{n-1} \sum_{t=1}^{n}\left(e_{i t}-\overline{\mathrm{e}}_{i t}\right)^{2}},
\end{gathered}
$$

where,

$e_{i t}=F R_{i, t^{-}} I R_{i, t}=$ difference in return of ETF $i$ and its underlying index at time $t$; $\overline{\mathrm{e}}_{i t}=$ sample mean difference; and

$n \quad=$ numbers of observation.

$\mathrm{TE}_{1}$ refer to the simple difference between the returns of the ETF and its underlying index. Positive (negative) $\mathrm{TE}_{1}$ indicates that the ETF has better (worse) return than the underlying index. Meanwhile, $\mathrm{TE}_{2}$ is the mean absolute deviation between the returns of ETF and its underlying index. $\mathrm{TE}_{3}$ refers to standard deviation of $\mathrm{TE}_{1}$. In general, the lower the tracking error, the better the tracking ability. 
Apart from calculated tracking errors, regression analysis technique is adopted to estimate the tracking ability of ETFs. In this analysis, the Ordinary Least Squares (OLS) model $F R_{i t}=$ $\alpha_{i}+\beta_{i} I R_{i t}+\varepsilon_{i t}$ is first estimated to obtain intercept or alpha coefficient $\left(\alpha_{i}\right)$, slope or beta $\left(\beta_{i}\right)$ coefficient and the coefficient of determination $\left(R^{2}\right)$. A positive (negative) sign of alpha indicates outperformance or excess profit (underperformance or excess loss) of the ETF against the underlying benchmark. Theoretically, it would be unlikely to get a positive figure for alpha because ETF is meant to replicate the benchmark index only. Nonetheless, according to Bassie (2012), ETFs may outperform its underlying benchmark when investors are confidence with underlying benchmark and thus willing to buy the ETF on premium. The beta coefficient represents rate of change of ETFs when the benchmark index changes by one percent. ETF that adopts perfect replication strategy towards its underlying index will have a beta of one. As such, the closer the beta to one, the better is the tracking performance. $R^{2}$ indicates how much of the variation in the ETF return is explained by variation in the return of the underlying index. It is another indicator for the tracking ability of an ETF (Aroskar et al., 2012). In this case, the higher the $R^{2}$, the better is the tracking ability.

\section{Empirical Results}

Table 2 below shows the tracking errors of ETFs listed in Bursa Malaysia against their underlying indices. The calculated $\mathrm{TE}_{1}$ values range from $-9.7018 \%$ (CIMBA40) to $9.8214 \%$ (MYETFDJ). Overall, the average TE1 values range from the lowest tracking error of $0.0092 \%$ (FBMKLCI-EA) to the higher tracking error of $0.1091 \%$ (CIMBC50). From another perspective, since $\mathrm{TE}_{1}$ is essentially the returns difference, it implies that, all ETFs outperformed their underlying indices in terms of simple weekly returns over the sample period of study.

Table 2. Calculated Tracking Errors

\begin{tabular}{|c|c|c|c|c|c|c|c|}
\hline \multirow[t]{2}{*}{ ETF } & \multirow[t]{2}{*}{ Sample Period } & \multirow[t]{2}{*}{$n$} & \multicolumn{3}{|l|}{$\mathbf{T E}_{1}$} & \multirow[t]{2}{*}{$\mathbf{T E}_{2}$} & \multirow[t]{2}{*}{$\mathbf{T E}_{3}$} \\
\hline & & & Min & Max & Mean & & \\
\hline METFAPA & $4 / 12 / 2015-27 / 5 / 2016$ & 25 & -2.2850 & 1.9101 & 0.0122 & 0.6788 & 0.8868 \\
\hline METFSID & $5 / 8 / 2015-27 / 5 / 2016$ & 53 & -3.5577 & 2.0685 & 0.0664 & 0.8864 & 1.1361 \\
\hline MYETFID & $21 / 3 / 2014-27 / 5 / 2016$ & 114 & -3.0665 & 2.6797 & 0.0335 & 0.8139 & 1.1084 \\
\hline CIMBC50 & $9 / 7 / 2010-27 / 5 / 2016$ & 307 & -5.5311 & 9.5543 & 0.1091 & 1.1340 & 1.5395 \\
\hline CIMBA40 & 9/7/2010 - 27/5/2016 & 307 & -9.7018 & 7.2361 & 0.0663 & 1.4300 & 1.9695 \\
\hline MYETFDJ & $31 / 1 / 2008-27 / 5 / 2016$ & 429 & -6.2909 & 9.8214 & 0.0292 & 0.9850 & 1.5236 \\
\hline $\begin{array}{l}\text { FBMKLCI- } \\
\text { EA }\end{array}$ & 20/7/2007 - 27/5/2016 & 461 & -5.8218 & 4.6890 & 0.0092 & 1.1215 & 1.4640 \\
\hline
\end{tabular}

Note: $\mathrm{TE}_{1}$ refers to the simple return difference between ETFs and underlying indices; $\mathrm{TE}_{2}$ refers to the mean absolute difference between ETF and underlying index; $\mathrm{TE}_{3}$ refers to standard deviation of $\mathrm{TE}_{1} . n, \mathrm{Min}, \mathrm{Max}$ represent sample size, minimum and maximum respectively.

As for $\mathrm{TE}_{2}$ which measures the average absolute mean return difference, METFAPA had the lowest tracking error $(0.6788 \%)$, whereas CIMBA40 had the highest tracking error $(1.4300 \%)$. Consistently, METFAPA and CIMBA40 had the lowest (0.8868\%) and the highest $(1.9695 \%)$ 
tracking error respectively by the $\mathrm{TE}_{3}$. Noting that $\mathrm{TE}_{3}$ is actually the standard deviation of the simple mean return difference, it means the simple mean return difference is the least (most) volatile in METFAPA (CIMBA40).

The weekly returns of ETFs and indices are further analyzed using regression analysis. The estimated results are summarised in Table 3. It is evident from Table 3 that all estimated $\alpha$ 's are positive, with the exception of METFAPA. It means these six ETFs had excess returns. Among the six ETFs that had positive $\alpha$, METFSID had the smallest $\alpha$ of 0.0124 , while CIMBC50 had the highest $\alpha$ of 0.0745 . In another words, excess returns are detected for these 6 ETFs with magnitude ranging from $0.0124 \%$ to $0.0745 \%$ per week. However, none of these excess returns are statistically siginificant. Results obtained from nonparametric test, namely the Wilcoxon Signed Ranks Test, confirmed that there was no significant excess return in all cases, see Table 4. This is evident since the null hypothesis of equal means in the returns of the ETF and its underlying index could not be rejected at conventional significance level.

As for the slope coeeficients, it is reported in Table 3 that the estimated $\beta$ 's range from 0.3611 (CIMBA40) to 0.8771 (METFAPA). They are all statistically difference from zero at conventional significance level. Furthermore, they are also statistically different from one with the exception of METFAPA. Since the estimated $\beta$ for METFAPA is indifferent from one, it implies that this ETF traced the underlying Thomson Reuters Islamic Asia Pacific ex-Japan Agribusiness Index perfectly well. Other ETFs that traced their underlying indices excellently well are MYETFID (0.8281), METFSID (0.7809), CIMBC50 (0.7719) and MYETFDJ (0.7510). On the other hand, FBMKLCI-EA (0.7510) performed moderately well while CIMBA40 (0.3611) performed poorly in tracing FTSE Bursa Malaysia KLCI Index and FTSE ASEAN 40 Index respectively.

Lastly, the $R^{2}$ value of 0.7972 for CIMBC50 implies that $79.72 \%$ of the variation in this ETF can be explained by variation in the underlying index. Meanwhile, only $26.13 \%$ of the variaiton in CIMBA40 could be explained by variation in its underlying index. That means $73.87 \%$ of its variation was due to factors other than the underlying index. In the context of tracking error, the higher the $R^{2}$, the better is the performance in the sense that the tracking error is lesser. Thus, CIMBC50 outperformed all other ETFs as it has the highest $R^{2}$ value, whereas the ETF that performed the worst is CIMBA40. 
Table 3. Regression Results

\begin{tabular}{|c|c|c|c|c|c|c|c|}
\hline ETF & $\alpha$ & $t(\alpha=0)$ & $\beta$ & $t(\beta=0)$ & $t(\beta=1)$ & $R^{2}$ & $n$ \\
\hline METFAPA & -0.003 & -0.016 & 0.8771 & $7.7274 * *$ & -1.0828 & 0.7308 & 25 \\
\hline METFSID & 0.0124 & 0.0805 & 0.7809 & $7.5300 * *$ & $-2.1127 *$ & 0.5314 & 53 \\
\hline MYETFID & 0.0407 & 0.396 & 0.8281 & $10.3005 * *$ & $-2.1382 *$ & 0.4887 & 114 \\
\hline CIMBC50 & 0.0745 & 1.0473 & 0.7719 & $34.5659 * *$ & $10.2144 * *$ & 0.7972 & 307 \\
\hline CIMBA40 & 0.0686 & 0.8837 & 0.3611 & $10.3691 * *$ & $\begin{array}{l}- \\
18.3462 * *\end{array}$ & 0.2613 & 307 \\
\hline MYETFDJ & 0.0331 & 0.4731 & 0.7510 & $19.9350 * *$ & $-6.6096 * *$ & 0.4797 & 429 \\
\hline $\begin{array}{l}\text { FBMKLCI- } \\
\text { EA }\end{array}$ & 0.0260 & 0.4137 & 0.6825 & $19.5700 * *$ & $\begin{array}{l}- \\
9.1040 * *\end{array}$ & 0.4554 & 461 \\
\hline
\end{tabular}

Notes: Equation $F R_{i t}=\alpha_{i}+\beta_{i} I R_{i t}+\varepsilon_{i t}$ is estimated. $\alpha$ refer to intercept from regression and $\beta$ refer to slope coefficient from regression. $R^{2}$ refers to how close is the data fitted onto the regression line. $n$ is the sample size. $t(\alpha=0)$ and $t(\beta=0)$ represent the $t$-ratio to test whether $\alpha$ and $\beta$ are statistically significantly difference from zero respectively. $t(\beta=1)$ represent the $t$-ratio to test whether $\beta$ is statistically significantly difference from one. * and ** represent significance at $5 \%$ and $1 \%$ level respectively.

Table 4. Wilcoxon Signed Ranks Test Results

\begin{tabular}{lll}
\hline ETF & $Z$ & $p$ \\
\hline METFAPA & 0.0000 & 1.0000 \\
METFSID & -0.7190 & 0.4720 \\
MYETFID & -0.8120 & 0.4170 \\
CIMBC50 & -1.2280 & 0.2190 \\
CIMBA40 & -0.6260 & 0.5310 \\
MYETFDJ & -0.2660 & 0.7900 \\
FBMKLCI-EA & -0.1430 & 0.8860 \\
\hline
\end{tabular}

Notes: $Z$ is the statistics of the test, and $p$ is the $p$-value of $Z$. The null hypothesis of equal means in the returns of the ETF and its underlying index is tested against the alternative hypothesis of unqual means in the returns of the two series. Based on the $p$-value, none lof the null hypothesis could be rejected at conventional significance level.

Table 5 summarizes the tracking errors of ETFs based on different measurements. It is evident that METFAPA consistently ranked number 1 in 3 out of 5 tracking error measurements. That means METFAPA outperformed all other ETFs from the perspectives of TE2, TE3 $\beta$. Meanwhile MYETFID consistently ranked second in 3 out of 5 tracking error measures. As for METFSID, it consistently ranked third in 4 out of 5 measurements. On the other hand, FBMKLCI-EA managed to appear top in the $\mathrm{TE}_{1}$ race, while CIMBC50 was able to secure the first position in th $R^{2}$ comparison exercise. On average, the performance of the ETFs in the ascending order average tracking errors is: METFAPA, MYETFID, METFSID, MYETFDJ, CIMC50, FBMKLCI-EA and CIMBA40. 
Table 5. Summary of Tracking Errors

\begin{tabular}{lllllll}
\hline ETF & TE1 & TE2 & TE3 & $\boldsymbol{\beta}$ & $\boldsymbol{R}^{2}$ & Average \\
\hline METFAPA & 2 & 1 & 1 & 1 & 2 & 1.4 \\
METFSID & 6 & 3 & 3 & 3 & 3 & 3.6 \\
MYETFID & 4 & 2 & 2 & 2 & 4 & 2.8 \\
CIMBC50 & 7 & 5 & 6 & 4 & 1 & 4.6 \\
CIMBA40 & 5 & 6 & 7 & 7 & 7 & 6.4 \\
MYETFDJ & 3 & 4 & 5 & 5 & 5 & 4.4 \\
FBMKLCI-EA & 1 & 7 & 4 & 6 & 6 & 4.8 \\
\hline
\end{tabular}

Note: Rank of ETF is given in this table with number 1 given to ETF with the smallest tracking error while number 7 given to ETF with the largest tracking error.

\section{Conclusion}

Exchange Traded Funds (ETFs) are pooled-investment funds that allow investors to own the undelying assets at the cheaptest way to massively diversify their investments. Since ETFs are invented to track the underlying indices, it is logic to evaluate their performances in terms of tracking errors. An ETF that traced the undelying index perfectly should produce zero trackimg error. Previous researches had documented significant tracking errors for ETFs in U.S., Europe stock as well as Asia-Pacifics stock markets. Malaysia stock market had introduced its first ETF in the year 2005, some 15 years after the listing of the world's first ETF in Canada.

The objective of this study is to measure the tracking errors of ETFs traded in Bursa Malaysia. Seven ETFs are included in this study. It is found that all the average TE1 values are positive and they range from $0.0092 \%$ (FBMKLCI-EA) to $0.1091 \%$ (CIMBC50). As $\mathrm{TE}_{1}$ is essentially measuring the difference between the returns of ETF and its underlying index, we can said that, all ETFs performed better than their underlying indices in terms of simple weekly return. The positive values of the estimated intercept coefficients $(\alpha)$ from simple regression analysis confirmed the existence of excess returns. However, results from both $t$-test and Wilcoxon Signed Ranks Test showed no statistical evidence of significant excess returns. As such, no ETFs had significantly outperformed their underlying indices. As for TE2, METFAPA had the lowest value $(0.6788 \%)$, whereas CIMBA40 had the highest value $(1.4300 \%)$. Consistently, METFAPA and CIMBA40 had the lowest (0.8868\%) and the highest (1.9695\%) TE 3 values.

The tracking error performance of these ETFs was also analysed by regressing the retuns of ETF on the returns of its underlying index. The estimated slope coefficient $(\beta)$ and the coefficient of determintion $\left(R^{2}\right)$ obtained served as two alternative measures of tracking error. All the estimated $\beta$ 's are significantly smaller than one, except METFAPA. It implies that METFAPA replicated the underlying index perfectly. Other ETFs that traced their underlying indices excellently well ( $\beta$ close to one) are MYETFID (0.8281), METFSID (0.7809), CIMBC50 (0.7719) and MYETFDJ (0.7510). From the perspective of $R^{2}$, CIMBC50 outperformed all other ETFs as it has the highest $R^{2}$ value, whereas the CIMB40 turned out to be the worst in tracking ability. Taking into consideration of all measures of tracking errors, 
the best ETF is MATFAPA with the least tracking error as a whole. The ranking of the remainder ETFs, in the ascending order of tracking error is MYETFID, METFSID, MYETFDJ, CIMC50, FBMKLCI-EA and CIMBA40 (highest tracking error). Noted that the top four ETFs are managed by i-VCAP Management.

The findings in this study is expected to provide clue for passive institutional and retail investors on their selection of ETF to mimic the portfolio of the desired underlying assets. Moreover, as tracking error is an indicator of a fund manager's skills, it is anticipated that these findings will motivate in improvement in the tracking ability of existing ETFs. In addition, since the trading volume of ETFs in Malaysia is still thin, more subsequent studies on ETF are encouraged for the development of new ETFs and to increase trading volume. Besides, Bursa Malaysia and Malaysian government should give promotion and tax reduction incentives respectively to ETFs investors to increase their participation.

\section{Acknowledgement}

The authors would like to thanks the editor and reviewers on thier comments that enhance the quality of our research work and the presentation of this version.

\section{Disclaimer}

The findings in this paper obtained from the sample data at hand during our study period, are to be observed with caution as it may not be valid for other sample periods. You should be aware of the risks that are associated with ETFs trading, and kindly seek advice from an independent financial advisor before you perform any transactions. Neither the authors, their institutions, nor the journal is held responsible for any transaction loss, if any, that you may have derived upon the findings of this article.

\section{Notes}

Note 1. ETFs are relatively new in Asia. The Nikkei 300 Index Fund, which was listed in May 1995, is the first ETF in Asia

Note 2. Some $90 \%$ of the ETFs are based in the United States (US) and Europe, while Asia Pacific had just started to grow rapidly in recently years.

Note 3. The dividends paid by stocks must be held until the ETF pays its dividend to shareholders.

Note 4. ABF Malaysia Bond Index Fund is excluded in this study.

\section{References}

Aroskar, R. \& Ogden, W. A. (2012). An Analysis of Exchange Traded Notes Tracking Errors with Their Underlying Indexes and Indicative Values. Applied Financial Economics, 22(24), 2047-2062. https://doi.org/10.1080/09603107.2012.684787

Bassie, L.(2012). The Performance And Tracking Ability of Exchange Traded Funds. (Masters' Thesis, Tilburg University). http://arno.uvt.nl/show.cgi?fid=122796 


\section{Al Macrothink}

Asian Journal of Finance \& Accounting

ISSN 1946-052X

2019, Vol. 11, No. 2

Blitz, D. \& Huij, J.,(2011). Evaluating the Performance of Global Emerging Markets Equity Exchange-Traded Funds. Emerging Markets Review, 13(2), 149-158. https://doi.org/10.1016/j.ememar.2012.01.004

Bursa Malaysia. (2017). Exchange Traded Funds (ETFs). Retreived from http://www.bursamalaysia.com/market/securities/equities/products/exchange-traded-fundsetfs/

Chu, P.K.K.,(2011). Study on the Tracking Errors and Their Determinants: Hong Kong Exchange Traded Funds (ETFs) Evidences. Applied Financial Economics, 21(5), 309-315. https://doi.org/10.2139/ssrn.1428768

Dingelstad, R. (2015). Tracking Error of Exchange-Traded Funds: Evidence from the UK. (Master Thesis, Maastricht University). http://hdl.handle.net/10362/15416

Elton, E. J., Gruber, M. J., Comer, G., \& Li, K. (2002). Spiders: Where Are the Bugs? Journal of Business, 75(3), 453-472. https://doi.org/10.1142/9789814335409_0012

Engle, R. \& Sakkar, D. (2006). Premium-Discount And Exchange Traded Funds. The Journal of Derivatives, 13(4), 27-45. https://doi.org/10.3905/jod.2006.635418

Gallagher, D.R. \& Segara, R. (2006). The Performance And Trading Characteristics Of Exchange-Traded Funds. Journal of Investment Strategy, 1(2), 49-60.

Gastineau, G. L. (2004). The Benchmark Index ETF Performance Problem. The Journal of Portfolio Management, 30(2), 96-103. https://doi.org/10.3905/jpm.2004.319935

Heino, A., \& Kromlid, S. (2014). Does size matter? The Effect of Assets under Management on Tracking Error in the American ETF Market. (Degree Thesis, University of Gothenburg)

Li, Y.Y. (2013). Performance Evaluation of Exchanged-Traded Funds in Emerging Market. (Masters Thesis, Saint Mary's University)

Lin, C.C., \& Chan, S.J. \& Hsu, H. (2005). Pricing efficiency of exchange traded funds in Taiwan. Journal of Asset Management. $\quad$ 7(1), 60-68. https://doi.org/10.1057/palgrave.jam.2240202

Milanos, N.T. \& Rompotis, G.G. (2006). Investing European ETFs: The Case of Swiss Exchange Traded Funds. The Annual Conference of HFAA, Thessaloniki, Greece. https://doi.org/10.2139/ssrn.929460

Prasanna, K.P. (2012). Performance of Exchange-Traded Funds in India. International Journal of Business Management, 7(23), 122-141. https://doi.org/10.5539/ijbm.v7n23p122 
Appendix

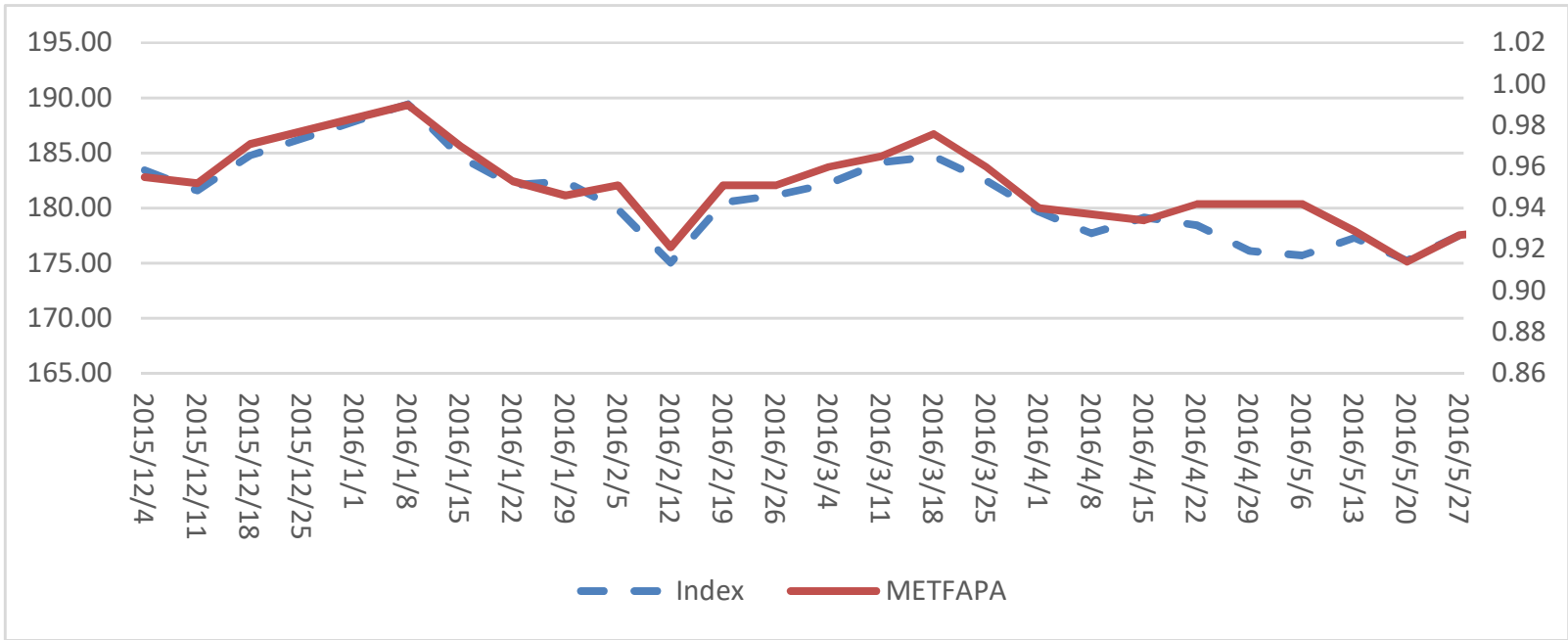

Figure 1. Plot of METFAPA and Thomson Reuters Islamic Asia Pacific ex-Japan Agribusiness Index

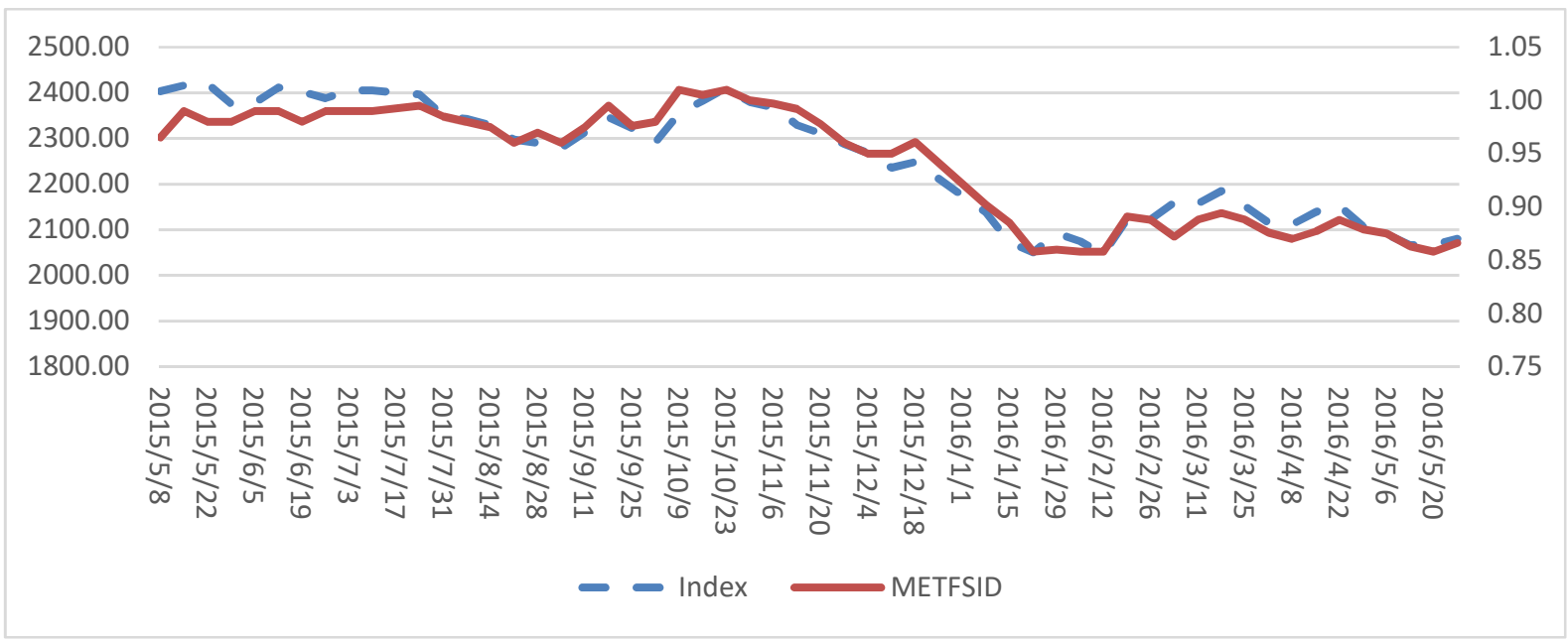

Figure 2. Plot of METFSID and MSCI SEA IMI Islamic High Dividend Yield 10/40 


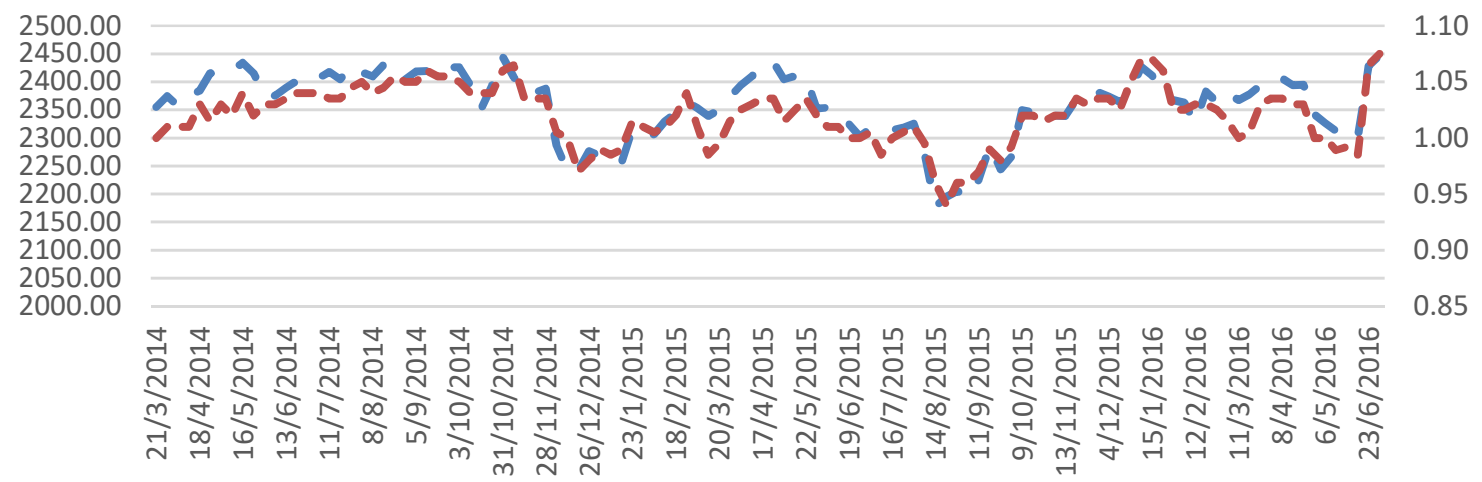

- Index - - MYETFID

Figure 3. Plot of MYETFID and MSCI Malaysia IMI Islamic High Dividend Yield 10/40

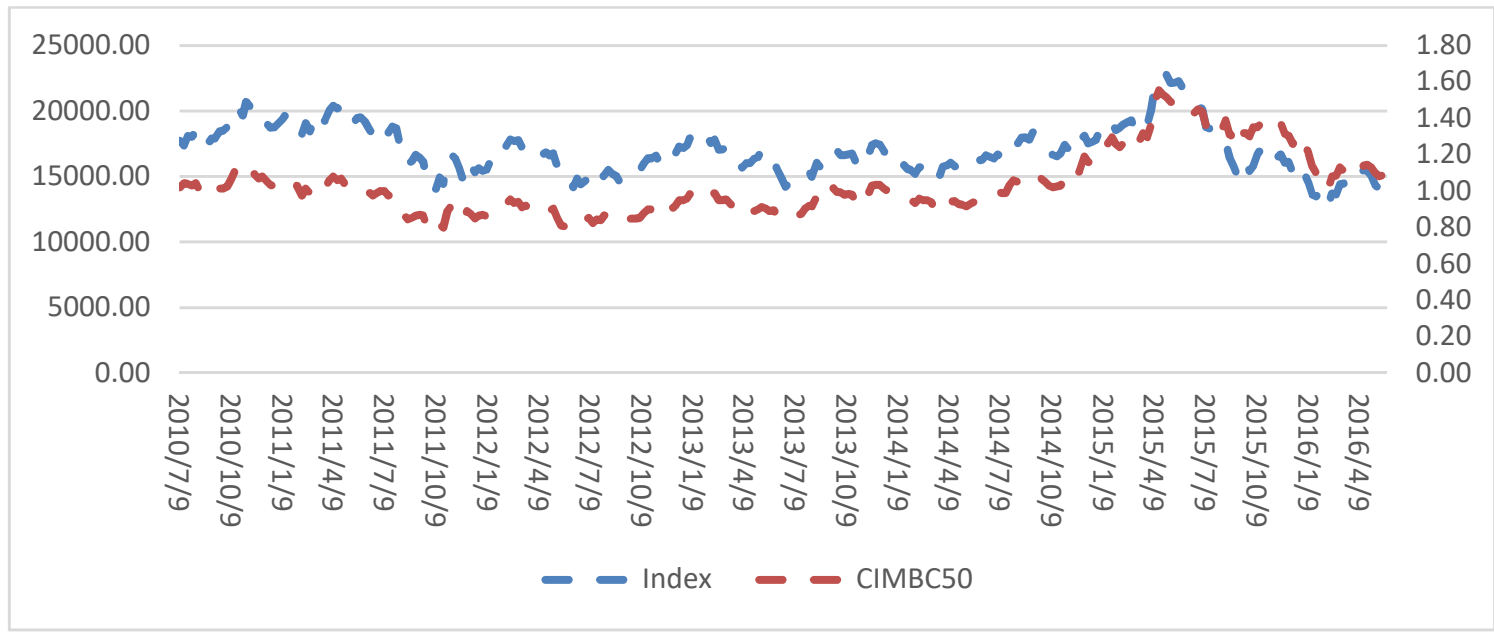

Figure 4. Plot of CIMBC50 and FTSE China 50 Index

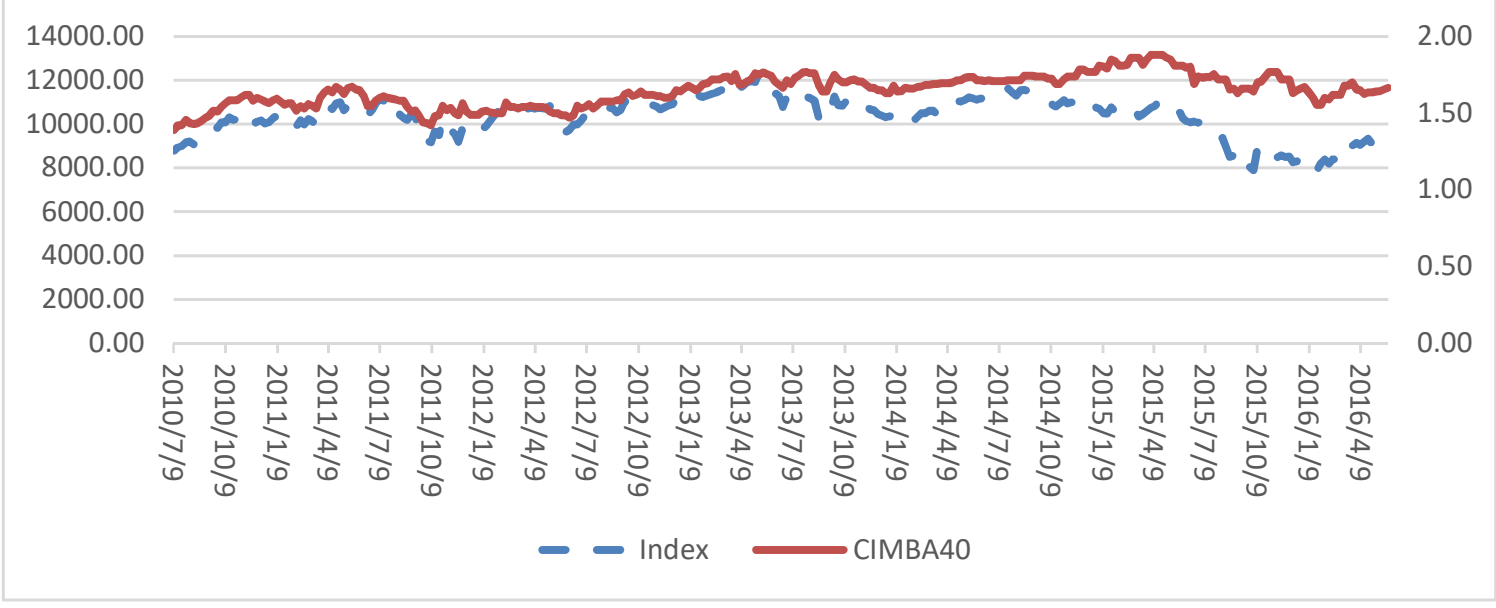

Figure 5. Plot of CIMBA40 and FTSE ASEAN 40 Index 


\section{Macrothink}

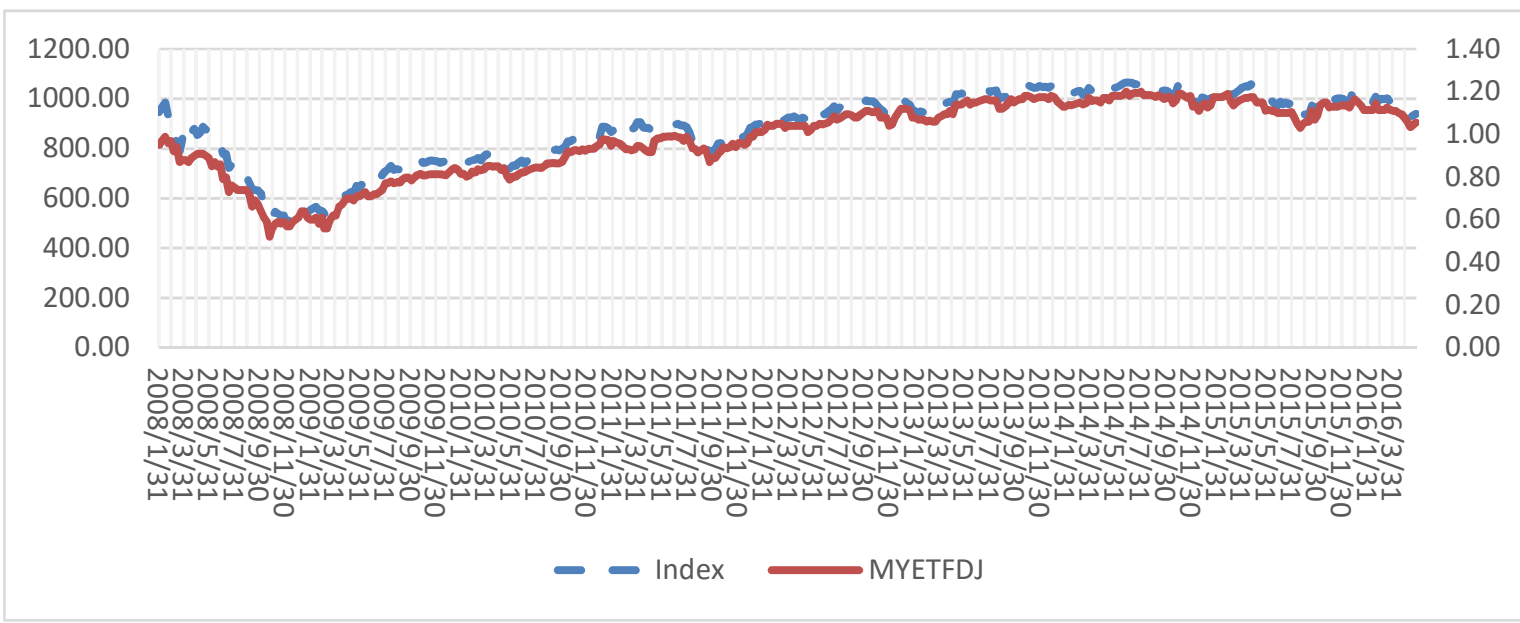

Figure 6. Plot of MYETFDJ and Dow Jones Islamic Market Malaysia Titans 25 Index

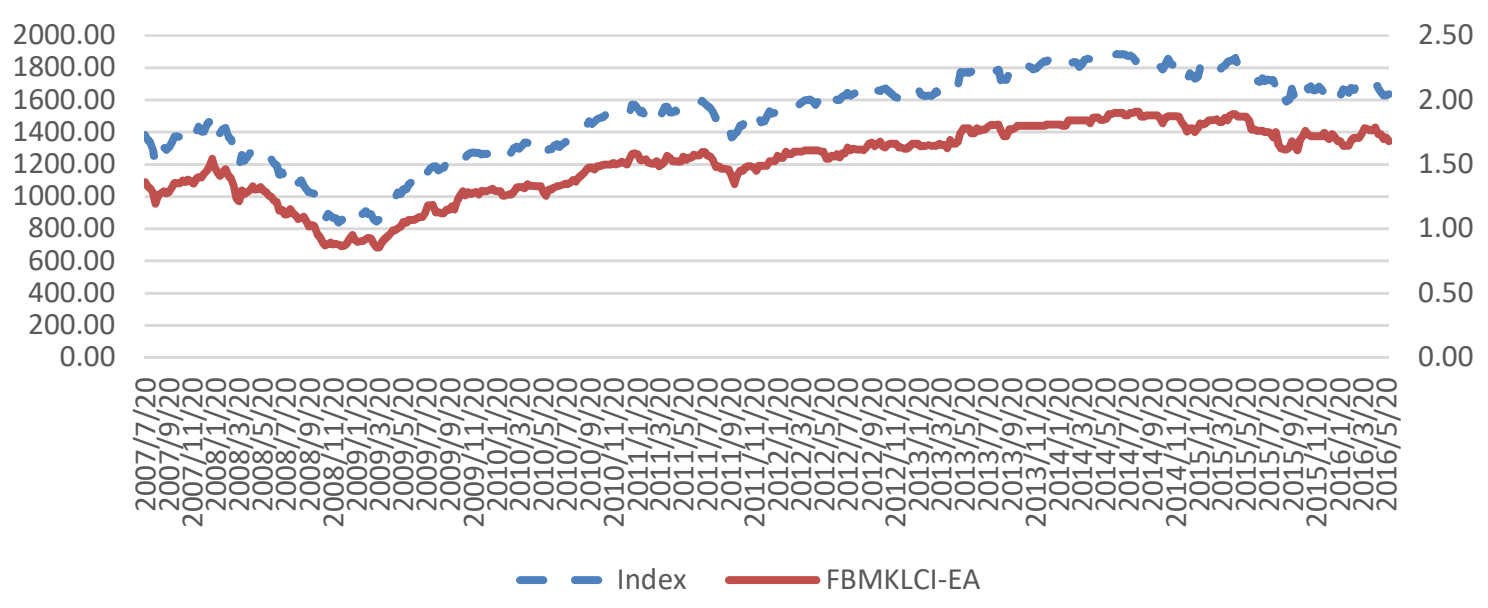

Figure 7. Plot of FBMKLCI-EA and FTSE Bursa Malaysia KLCI Index 